\title{
Relation of Mesangial IgA Glomerulonephritis to Polymorphism of Immunoglobulin Heavy Chain Switch Region
}

\author{
A. G. Demaine, M. Rambausek, ${ }^{\star}$ J. F. Knight, D. G. Williams, K. I. Welsh, and E. Ritz ${ }^{\star}$ \\ Departments of Molecular Immunogenetics and Renal Medicine, Guy's Hospital, London, United Kingdom; \\ and ${ }^{*}$ Department of Internal Medicine, Heidelberg, Federal Republic of Germany
}

\begin{abstract}
We have investigated the switch regions of $\mathrm{Ig}$ heavy chain genes of patients with IgA glomerulonephritis (IgA-GN) using restriction fragment length polymorphism (RFLP) analysis. Genomic DNA from patients and controls was digested with the restriction endonuclease Sst $I$ and transferred to nylon membranes using the Southern blot procedure and hybridized with a probe homologous to the switch region of the Ig $\mathrm{C} \mu$ gene $(S \mu)$ which detects RFLPs in both $S \mu$ and the switch region of the Ig $\mathbf{C} \alpha 1$ gene (S $\alpha 1)$. A significant decrease in the frequency of the 2.6;2.1 kb heterozygous $S \mu$ phenotype was found in patients with IgA-GN $(P=0.003)$. With respect to the $S \alpha 1$ region, there was a significant increase in the frequency of the $7.4 \mathrm{~kb} S \alpha 1$ phenotype $(P=0.002)$. In addition, a significant increase in the frequency of the $7.4 \mathrm{~kb} \mathrm{~S} \alpha 1$ allele was found $(P$ $=0.0002)$. These results suggest that gene(s) within the Ig heavy chain loci may be important in the pathogenesis of IgA-GN.
\end{abstract}

\section{Introduction}

In many countries IgA glomerulonephritis (IgA-GN) ${ }^{1}$ is the most common form of glomerulonephritis, accounting for $20-30 \%$ of biopsy-confirmed cases according to the country in which the study was performed (1). Several clinical observations point to a genetic predisposition being important in its pathogenesis. First, IgA-GN may be familial (2) and it also occurs in siblings (3). Second, IgA-GN is associated with inherited complement defects and Ig kappa light chain allotypes $(4,5)$. Finally, subtle immunological abnormalities have been recognized in healthy relatives of patients with IgA-GN, including the presence of cold-reacting anti-nuclear factor and IgA bearing peripheral blood lymphocytes $(6,7)$.

Address all correspondence to Dr. A. G. Demaine, Department of Medicine, Kings College Hospital, London, SE5 8RX, England.

Received for publication 31 December 1986 and in revised form 25 June 1987.

1. Abbreviations used in this paper: GN, glomerulonephritis; RFLP, restriction fragment length polymorphism; $\mathrm{S} \alpha 1, \operatorname{Ig} \mathrm{C} \alpha 1$ switch region; $\mathrm{S} \mu$, Ig C $\mu$ switch region; SSC, standard saline citrate.

J. Clin. Invest.

(c) The American Society for Clinical Investigation, Inc.

0021-9738/88/02/0611/04 \$2.00

Volume 81, February 1988, 611-614
The circumstantial evidence for immunogenetic factors prompted us to examine Ig heavy chain switch region polymorphism in patients with IgA-GN. The switch regions of Ig heavy chain genes are highly repetitive sequences and mediate the Ig isotype switch, for instance from IgM to IgG. They occur on the $5^{\prime}$ side of all functional Ig constant heavy chain genes except $C \delta$. The repetitive nature of the switch sequences means that cross-hybridization occurs when a switch region probe is used. Hence a DNA probe homologous to the Ig $\mathrm{C} \mu$ switch region $(\mathrm{S} \mu)$, when used in conjunction with Sst I restriction endonuclease, can detect restriction fragment length polymorphism (RFLP) in $\mathrm{S} \mu$ and also the switch region flanking the Ig $\mathrm{C} \alpha 1$ gene (S $\alpha 1)$ (8); other switch regions are also detected but the polymorphisms occur at a very low frequency (8). A total of six independent loci can be identified, five of which are in strong linkage disequilibrium. They give rise to 28 different haplotypes that segregate in a Mendelian fashion. Therefore a large portion of the Ig constant heavy chain gene loci can be investigated using one probe. Using a similar $S \mu$ probe, this DNA region has recently been shown to be associated with other forms of immunologically mediated renal disease, including membranous nephropathy $(9,10)$. The results presented here indicate that IgA-GN is also associated with the Ig heavy chain loci.

\section{Methods}

\section{Subjects}

IgA-GN. 48 patients with biopsy-proven IgA-GN were studied. The majority were young males (30) with recurrent macroscopic hematuria and all had normal renal function. Ages ranged from 5 to $72 \mathrm{yr}$ (mean age $32.3 \pm 12.9 \mathrm{yr}$ ). No patient had experienced purpuric rash, joint pain, or other symptoms of systemic vasculitis.

Controls. We studied 141 normal caucasoid healthy controls with no history of renal dysfunction.

\section{DNA extraction and hybridization}

Each subject had $25-35 \mathrm{ml}$ of peripheral venous blood collected into $5 \%$ EDTA. High molecular weight DNA was extracted from the peripheral blood leukocytes of patients and controls. 8-10 $\mu \mathrm{g}$ of DNA was digested with the restriction endonuclease Sst I (Bethesda Research Laboratories, Glasgow, United Kingdom), size fractionated by electrophoresis in $0.6 \%$ agarose horizontal gels, and transferred onto nylon membrane filters (Hybond-N, Amersham International, Amersham, Buckinghamshire, England) using the method of Southern (11). Filters were hybridized for $20-24 \mathrm{~h}$ to a probe homologous to the $\mathrm{S} \mu$ region which had been oligolabeled with ${ }^{32}$ deoxycytidine ribonucleotide triphosphate. Washes to remove nonspecifically bound probe were carried out in $0.3 \times \mathrm{SSC}, 0.5 \% \mathrm{SDS}$ for $30 \mathrm{~min}$ at $65^{\circ} \mathrm{C}$. Filters were placed in Cronex daylight cassettes between Kodak XAR 5 film with two 


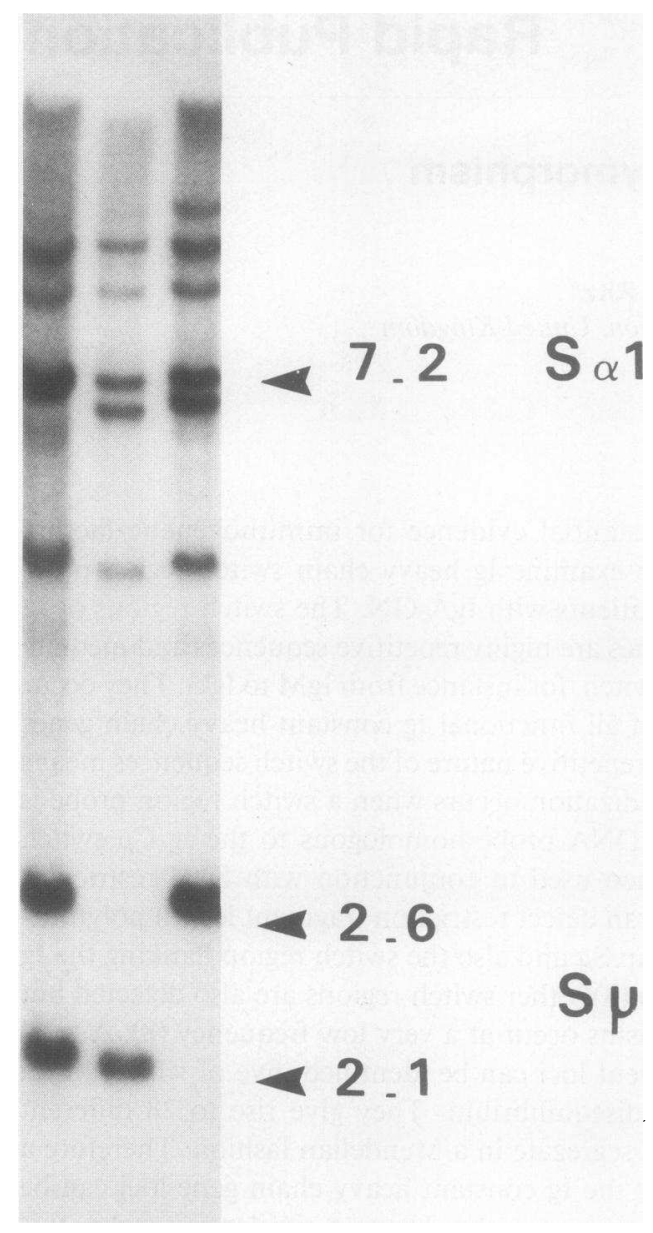

Figure 1. The $S \mu$ probe in conjunction with the restriction endonuclease Sst I detects polymorphisms at the $S \mu$ and $S \alpha 1$ loci (7). Allelic fragments of 2.6 or $2.1 \mathrm{~kb}$ are detected at the $S \mu$ locus and 7.4 and $6.9 \mathrm{~kb}$ at the $S \alpha 1$ locus. Common phenotypes are shown in the figure. The left lane is a $2.6 ; 2.1-\mathrm{kb} \mathrm{S} \mu-7.4-\mathrm{kb} \mathrm{S} \alpha 1$ phenotype; the middle lane is a $2.1-\mathrm{kb} \mathrm{S} \mu-7.4 ; 6.9-\mathrm{kb} S \alpha 1$ phenotype; and the right lane is a $2.6-\mathrm{kb} \mathrm{S} \mu-7.4 ; 6.9-\mathrm{kb} \mathrm{S} \alpha 1$ phenotype. The other bands in the autoradiograph are due to cross-hybridization with other switch sequences but they are generally nonpolymorphic and are not discussed.

intensifying screens (Du Pont Co., Diagnostic and Bio Research Systems, Wilmington, DE) at $-70^{\circ} \mathrm{C}$. Films were developed at 24 and $72 \mathrm{~h}$.

\section{DNA probe}

The probe used $\left(S_{\mu}\right)$ was a $2.1-\mathrm{kb}$ Sst I fragment from the clone C75RIB (obtained from Dr. T. H. Rabbitts, Medical Research Centre, Cambridge), which is an 8-kb Eco RI fragment of the whole $S \mu$ region that had been inserted into the vector pACYC184 (12).

The $S \mu$ probe in conjunction with the endonuclease Sst I detects polymorphic fragments of 2.1 or $2.6 \mathrm{~kb}$ which are allelic, giving phenotypes of $2.1 ; 2.1,2.6 ; 2.6$, or $2.1 ; 2.6 \mathrm{~kb}$. With respect to the $\mathrm{S} \alpha 1$ loci, allelic fragments of 7.4 or $6.9 \mathrm{~kb}$ are detected (Fig. 1). The following $\mathrm{S} \mu$ and $S \alpha 1$ haplotypes were defined in those individuals who were homozygous for at least one locus: $2.6 ; 7.4,2.6 ; 6.9,2.1 ; 7.4$, and $2.1 ; 6.9 \mathrm{~kb}$.

\section{Statistical analysis}

Statistical comparisons were made using Fisher's exact test. Etiological fraction and relative risk were also calculated (13).

\section{Results}

The results of the phenotypic expression of the $S \mu$ and $S \alpha 1$ alleles using RFLP analysis are shown in Table I. In the patient group there was a decrease in the heterozygous phenotype 2.6; $2.1 \mathrm{~kb}$ (33.3 vs. $56.0 \%$ in controls, $P=0.003$ ). This was accompanied by increases in both the 2.6- and $2.1-\mathrm{kb}$ putative homozygous phenotypes. With respect to the $S \alpha 1$ loci there was almost complete absence of homozygotes for the $6.9-\mathrm{kb} S \alpha 1$ phenotype, accompanied by a significant increase in the proportion homozygous for the 7.4-kb phenotype $(P=0.002)$.

The gene frequencies of the individual alleles are shown in Table II. Patients with mesangial IgA-GN have a significant excess of the $S \alpha 17.4-\mathrm{kb}$ allele ( 0.802 vs. 0.609 in controls, $P$ $=0.0002$ ). In contrast, no significant difference of gene frequency was noted for the alleles of the $S \mu$ locus.

The frequency of the putative heplotypes is shown in Table III. The frequency of the $2.1 ; 6.9-\mathrm{kb}$ haplotype was significantly decreased in the patient group $(0.1$ vs. 0.213 in controls, $P$ $=0.01$ ). There was a compensatory increase in the frequency of the 2.6;7.4- and $2.1 ; 7.4-\mathrm{kb}$ haplotypes $(P=0.04$ and 0.07 , respectively).

Hardy-Weinberg analysis showed that in caucasoids of West- and Mid-European origins the $S \mu$ and $S \alpha 1$ alleles examined comprised $>99.3 \%$ of all possible alleles. There is a suggestion that in uremia artefactual RFLPs may appear (14). However, none of the patients studied was uremic, and no fragments of unusual electrophoretic mobility were noted,

Table I. Phenotypic Expression of $S \mu$ and Sal Alleles by RFLP Analysis

\begin{tabular}{|c|c|c|c|c|c|c|c|}
\hline \multirow[b]{2}{*}{$\mathrm{S}_{\mu}$} & \multicolumn{2}{|c|}{ Controls } & \multicolumn{2}{|c|}{ IgA-GN } & \multirow{2}{*}{$\begin{array}{l}P \\
\text { (vs. controls) }\end{array}$} & \multirow[b]{2}{*}{$\begin{array}{l}\text { Etiological } \\
\text { fraction }\end{array}$} & \multirow[b]{2}{*}{$\begin{array}{l}\text { Relative } \\
\text { risk }\end{array}$} \\
\hline & $n$ & $(\%)$ & $n$ & $(\%)$ & & & \\
\hline $2.6 ; 2.1$ & $79^{*}$ & 56.0 & 16 & 33.3 & 0.003 & & 0.39 \\
\hline 2.6 & 28 & 19.9 & 15 & 31.3 & 0.04 & 0.14 & 1.8 \\
\hline 2.1 & 34 & 24.1 & 17 & 35.4 & 0.05 & 0.15 & 1.7 \\
\hline \multicolumn{8}{|l|}{$\mathbf{S} \alpha 1$} \\
\hline $7.4 ; 6.9$ & 64 & 46.4 & 17 & 35.4 & 0.06 & & 0.63 \\
\hline 7.4 & 52 & 37.7 & 30 & 62.5 & 0.002 & 0.4 & 2.8 \\
\hline 6.9 & 22 & 15.9 & 1 & 2.1 & 0.006 & & 0.11 \\
\hline
\end{tabular}

The restriction endonuclease Sst I was used in conjunction with the $\mathrm{S} \mu$ probe. Allelic fragments of 2.6 or $2.1 \mathrm{~kb}$ (S $\mu$ switch region) and 7.4 or $6.9 \mathrm{~kb}(\mathrm{~S} \alpha 1$ switch region) are detected. Statistical calculations were carried out using Fisher's exact test ( $P$ value). Relative risk and etiological fraction were also calculated. * Includes two subjects with rare fragment bands (complete phenotypes: 2.6;2.5 and 2.6;2.2 kb) 
Table II. Genotypes of $S \mu$ and Sal Alleles by RFLP Analysis in Mesangial IgA-GN

\begin{tabular}{|c|c|c|c|c|}
\hline & \multicolumn{2}{|l|}{$\mathbf{S}_{\mu}$} & \multicolumn{2}{|l|}{$\mathrm{S} \alpha \mathbf{1}$} \\
\hline & 2.6 & 2.1 & 6.9 & 7.4 \\
\hline Controls & 0.475 & 0.518 & 0.391 & 0.609 \\
\hline IgA-GN & 0.479 & 0.521 & 0.198 & $0.802^{*}$ \\
\hline
\end{tabular}

Gene frequencies were calculated for the individual alleles. The control population conformed to the Hardy-Weinberg equation with respect to both the $S \mu$ and $S \alpha 1$ loci.

* Versus frequency in controls; $P$ value $=0.0002$.

though two control samples did have bands of unusual mobility.

\section{Discussion}

The consequences of polymorphism in Ig heavy chain switch region for Ig function have not been defined in humans. By analogy with data in the mouse (15) it is likely, however, that differences in switch region sequences are associated with alterations in immune repertoire expression. Since switch region polymorphism may be associated with differences of the variable heavy chain region genes, it is conceivable that altered $\mathrm{S} \mu$ and $S \alpha 1$ genotypes and phenotypes are secondary to restrictions in the antigen recognition repertoire. In a recent study, plasma from patients with mesangial IgA-GN, but not controls, interacted with a glomerular basement membrane epitope, a finding also consistent with restriction of the recognition mechanism (16). Similar considerations apply to the recent recognition of polymorphism of the Ig heavy chain switch region in other histological types of glomerulonephritis (9). On the other hand, the association with switch region polymorphisms may be related to the constant region via a feature of the expressed product, for example isoelectric point and ability to activate complement. In this context it is of note that in

Table III. Frequency of $S \mu-S \alpha 1$ Haplotypes in IgA-GN by RFLP Analysis

\begin{tabular}{|c|c|c|c|c|}
\hline \multirow{2}{*}{$\begin{array}{l}\text { Haplotype } \\
S_{\mu} / \mathrm{S} \alpha 1\end{array}$} & \multicolumn{2}{|c|}{ IgA-GN } & \multicolumn{2}{|c|}{ Controls } \\
\hline & $n$ & Freq. & $n$ & Freq. \\
\hline \multicolumn{5}{|l|}{$k b$} \\
\hline $2.6 ; 7.4$ & 35 & 0.427 & 49 & 0.327 \\
\hline $2.6 ; 6.9$ & 4 & 0.05 & 15 & 0.1 \\
\hline $2.1 ; 7.4$ & 35 & 0.427 & 54 & 0.36 \\
\hline $2.1 ; 6.9$ & 8 & $0.1^{*}$ & 32 & 0.213 \\
\hline Total $=$ & 82 & & 150 & \\
\hline
\end{tabular}

$\mathrm{S} \mu / \mathrm{S} \alpha 1$ haplotypes were designated as follows: $2.6 ; 7.4,2.6 ; 6.9$, $2.1 ; 7.4$, and 2.1;6.9 kb. Assignment of haplotypes was possible in 41 patients and 75 controls. There was a significant decrease in the frequency of the 2.1;6.9-kb haplotype in the patient group compared with controls, which was accompanied by an increase in frequency of the 2.6;7.4- and 2.1;7.4-kb haplotypes.

* Versus frequency in controls; $P$ value $=0.01$. patients with mesangial IgA-GN, elution of IgA deposited in the glomerulus revealed pI restriction (17).

Although the frequency of the $S \mu$ alleles is not significantly different in IgA-GN, the $S \mu$ phenotypes are not in HardyWeinberg equilibrium, as there is a significant reduction in the number of $S \mu$ heterozygotes. This suggests that they are resistant to the development of the disease. In contrast, at the $\mathbf{S} \alpha \mathbf{1}$ locus the 7.4-kb allele and the 7.4-kb phenotype are associated with IgA-GN, indicating that the $S \alpha 1$ allele may be a risk factor for susceptibility to IgA-GN. These results suggest that there may be two separate associations of IgA-GN with Ig switch regions, one with $S \mu$ and the other with $S \alpha 1$. At the moment it is unclear if these markers are present on the same chromosome or two different ones. Analysis of the haplotypes suggests that both the 2.6;7.4- and the 2.1;7.4-kb haplotypes are increased in IgA-GN, with a decreased frequency of the 2.1;6.9-kb haplotype. Further studies using multiply affected families may help to resolve this.

The magnitude of change in switch region allele frequencies and phenotype frequencies is such that our observation has currently no diagnostic value. However, in other immune diseases it can be shown that simultaneous consideration of different markers, even when coded on different chromosomes, increases the relative risk of disease. One example is the connection between Ig switch region, T cell receptor, and HLA phenotypes in myasthenia gravis (18). In view of the known association of mesangial IgA-GN with genetic abnormalities of complement factors; allotypes of complement factors $\mathrm{C} 3$, factor B, and Ig kappa light chain $(4,5)$; and the inconsistent evidence of an association with HLA-B and HLA-DR (19), the findings reported here may gain substantial importance in association with other disease markers.

\section{Acknowledgments}

We would like to thank Dr. T. H. Rabbitts for kindly providing the DNA probe used in this study.

This work was partly supported by a grant from the National Kidney Research Fund (United Kingdom), the Special Trustees of Guy's Hospital, and Deutsche Forschungsgeneinfehaft (Ra 367 I.I) (Federal Republic of Germany).

All DNA modifying enzymes, electrophoresis materials, and equipment were obtained from Bethesda Research Laboratories, Glasgow, United Kingdom.

\section{References}

1. Clarkson, A. R., A. J. Woodroffe, K. M. Bannister, J. D. Lomax-Smith, and I. Aarons. 1984. The syndrome of IgA nephropathy. Clin. Nephrol. 21:7-14.

2. Julian, B. A., P. A. Quiggins, J. S. Thompson, S. Y. Woodford, K. Gleason, and R. J. Wyatt. 1985. Familial IgA nephropathy. Evidence of an inherited mechanism of disease. N. Engl. J. Med. 312:202-208.

3. Sabatier, J. C., C. Genin, H. Assenat, S. Colon, F. Ducret, and F. C. Berthoux. 1979. Mesangial IgA glomerulonephritis in HLA identical brothers. Clin. Nephrol. 11:35-38.

4. Wyatt, R. J., B. A. Julian, A. Weinstein, N. F. Rothfield, and R. H. McClean. 1982. Partial H (BIH) deficiency and glomerulonephritis in two families. J. Clin. Immunol. 2:110-117.

5. Le Petit, J. D., E. van Loghem, G. de Lange, F. C. Berthoux, C. Chapuis-Cellier, and J. L. Serre. 1981. Gm, Am, Pi, and Km markers in mesangial glomerulonephritis. J. Immunogenet. (Oxf.). 8:415-418.

6. Nomoto, Y., M. Miura, M. Endoh, Y. Tomino, and H. Sakai. 
1984. Cold reacting anti-nuclear factor (ANF) in families of patients with IgA nephropathy. Clin. Exp. Immunol. 58:63-67.

7. Sakai, H., Y. Nomoto, S. Arimori, K. Komori, H. Inouye, and K. Tsuji. 1978. Increase of IgA-bearing peripheral blood lymphocytes in families of patients with IgA nephropathy. Am. J. Clin. Pathol. 72:452-456.

8. Migone, N., J. Feder, H. Cann, B. van West, J. Hwang, N. Takahashi, T. Honjo, A. Piazza, and L. L. Cavalli-Sforza. 1983. Multiple DNA fragment polymorphisms associated with immunoglobulin $\mu$ chain switch-like regions in man. Proc. Natl. Acad. Sci. USA. 80:467471.

9. Demaine, A. G., D. H. Taube, R. W. Vaughan, L. A. P. Kerr, and K. I. Welsh. 1986. Immunoglobulin heavy chain switch region restriction fragment length polymorphisms are associated with renal disease. Clin. Exp. Immunol. 66:406-413.

10. Demaine, A. G., R. W. Vaughan, D. H. Taube, and K. I. Welsh. 1988. Association of membranous nephropathy with $\mathrm{T}$ cell receptor constant beta chain and immunoglobulin heavy chain switch region polymorphisms. Immunogenetics. 27:19-23.

11. Southern, E. 1975. Detection of specific sequences among DNA fragments separated by gel electrophoresis. J. Mol. Biol. 98:503-517.

12. Flanagan, J. G., and T. H. Rabbitts. 1982. Arrangement of human immunoglobulin heavy chain constant region genes implies evolutionary duplication of a segment containing $\mathrm{y}, \mathrm{e}$, and a genes. Nature (Lond.). 300:709-716.
13. Svejgaard, A., C. Jersild, L. Staub Neilsen, and W. F. Bodmer. 1974. HL-A antigens and disease: statistical and genetical associations. Tissue Antigens. 4:95-105.

14. Demaine, A. G., K. I. Welsh, R. W. Vaughan, and D. H. Taube. 1985. Immunoglobulin $\mathrm{Cu}$ gene restriction fragment length polymorphisms associated with chronic renal failure. Immunol. Lett. 9:149152.

15. Mowatt, M., and W. A. Dunnick. 1986. DNA sequence of the murine y1 switch segment reveals novel structural elements. J. Immunol. 136:2674-1683.

16. Cederholm, B., J. Wieslander, P. Bygren, and D. Heinegard. 1986. Patients with IgA nephropathy have circulating anti-basement membrane antibodies reacting with structures common to collagen I, II and IV. Proc. Natl. Acad. Sci. USA. 83:6151-6155.

17. Monteiro, R. C., L. Halbwachs-Mecarelli, M. C. Roque-Barreira, L. Noel, J. Berger, and P. Lesavre. 1985. Charge and size of mesangial IgA in IgA nephropathy. Kidney Int. 28:666-671.

18. Demaine, A. G., K. I. Welsh, N. Willcox, and J. NewsomDavis. 1987. Genetic susceptibility to myasthenia gravis studied by DNA hybridisation using immunoglobulin and $\mathrm{T}$ cell receptor probes. Ann. NY Acad. Sci. 505:800-802.

19. Egido, J., J. Sancho, R. Blasco, L. Lozano, and L. Hernando. 1984. Immunological aspects of IgA nephropathy in humans. In Nephrology: Proceedings of the IX International Congress of Nephrology. R. R. Robinson, editor. Springer-Verlag, New York. 652-664. 